\title{
In Vitro Antioxidant Activity of Hydrophila auriculata Leaves Extract and Silver Nanoparticles
}

\author{
M. Ravishankar*, V. Christibai Juliet Esther \\ Department of Chemistry, Rajah Serfoji Government College, Thanjavur - 613 005, Tamil Nadu, India.
}

\section{ARTICLE DETAILS}

Article history:

Received 02 October 2018

Accepted 23 October 2018

Available online 11 November 2018

\section{Keywords:}

Hydrophila auriculata

Silver Nanoparticles

Antioxidant

\begin{abstract}
A B S T R A C T
Antioxidant activity of Hydrophila auriculata leaf extract and silver nanoparticles (AgNPs) were carried out for proving its utility in free radical mediated diseases. The flower extract and silver nanoparticles were screened for in vitro antioxidant activity by oxygen radical scavenging such as DPPH, total antioxidant assay and superoxide radical scavenging activity at different concentrations. The antioxidant potential was found to be dose dependent. AgNPs possess probable antioxidant activity as compared with Hydrophila auriculata leaf extract and near to the standard. It is an obvious indication that the resulting activity of the AgNPs is not due to any capping agents, which are found in minute amounts but is due to the elemental silver.
\end{abstract}

\section{Introduction}

The human body has a complex system of natural enzymatic and nonenzymatic antioxidant defenses which counteract the harmful effects of free radicals and other oxidants [1]. Free radicals are accountable for producing a large number of sicknesses including cardiovascular disease, cancer, Alzheimer's disease, neural disorders mild cognitive impairment, Parkinson's disease, alcohol induced liver disease, ulcerative colitis, aging and atherosclerosis [2,3]. Defense against free radicals can be improved by plenty consumption of dietary antioxidants. Significant proof indicates that foods having antioxidants and probably in particular the antioxidant nutrients may be of major importance in disease prevention. There is, however, a growing consensus among scientists that a combination of antioxidants, rather than single entities, may be more effective over the long term [4]. Antioxidants may be of great benefit in improving the quality of life by preventing or postponing the onset of degenerative diseases. In addition, they have a possible for important savings in the cost of health care delivery. Various methods are used to investigate the antioxidant property of samples (diets, plant extracts, commercial antioxidants etc.) [5]. The present study was to investigate the antioxidant activity of Hydrophila auriculata leaves extract and AgNPs.

\section{Experimental Methods}

\subsection{Chemicals}

All the experiments were conducted at room temperature. Materials used for the synthesis of silver nanoparticles were AR grade silver nitrate $\left(\mathrm{AgNO}_{3}\right)$ purchased from Merck, India.

\subsection{Hydrophila auriculata Leaves Collection}

The Hydrophila auriculata leaves were collected in January 2015 from Kurungalam Village, Thanjavur district, Tamil Nadu from a single herb. The leaves were recognized and authenticated by Dr. S. John Britto, Director, Rapiant Herbarium and Centre for molecular systematics, St. Joseph's college Trichy, Tamilnadu. India. A specimen voucher has been placed at the Rabinat Herbarium, St. Josephs College, Thiruchirappalli, Tamilnadu, India.

\subsection{Synthesis of Ag Nanoparticles using Leaf Extracts}

The dried leafs were pulverized well with mortar and pestle to make a powder. Twenty grams of powder sample was mixed with $100 \mathrm{~mL}$ of deionized water and the mixture was boiled for $10 \mathrm{~min}$. The leaf extract was filtered with Whatman No. 1 filter paper after cooling. The filtrate was kept at $4{ }^{\circ} \mathrm{C}$ for further use.

For the Ag nanoparticles synthesis, $5 \mathrm{~mL}$ of Hydrophila auriculata leaf extract was added to $45 \mathrm{~mL}$ of $1 \mathrm{mM}$ aqueous $\mathrm{AgNO}_{3}$ solution in a $250 \mathrm{~mL}$ Erlenmeyer flask. The flask was then incubated in dark for $5 \mathrm{~h}$ (to minimize the photo activation of silver nitrate), at room temperature. A control was kept without leaf extract. The Ag nanoparticle solution thus obtained was purified by repeated centrifugation at 10,000 rpm for $15 \mathrm{~min}$ followed by re-dispersion of the pellet in de-ionized water. Then the Ag nanoparticles were freezed and dried for using antioxidant activity [6].

\subsection{In Vitro Antioxidant Activity}

DPPH (1, 1-diphenyl-2-picrylhydrazyl) radical-scavenging activity was determined by the method of Shimada et al., [7]. The scavenging activity of the Hydrophila auriculata towards superoxide anion radicals was measured by the method of Liu et al., [8]. The total antioxidant activity of the extract was evaluated by the phosphomolybdenum method according to the procedure of Prieto et al., [9]. The chelating activity of the AgNPs and plant extract for ferrous ions $\mathrm{Fe}^{2+}$ was measured according to the method of Dinis et al., [10]. The $\mathrm{Fe}^{3+}$ reducing power of the extract was determined by the method of Oyaizu [11].

\section{Results and Discussion}

Antioxidants may be of great advantage in improving the quality of life by preventing or postponing the onset of degenerative diseases. In addition, they have a potential for substantial savings in the cost of health care delivery. Various methods are used to investigate the antioxidant property of samples (diets, plant extracts, commercial antioxidants etc.) [5]. Our earlier reports noticed that the green synthesis, characterization and evaluation of antimicrobial activity of silver nanoparticles from Hygrophila auriculata leaf extract [12]. This present study was to investigate the antioxidant activity of Hydrophila auriculata leaf extract and AgNPs.

\subsection{DPPH Scavenging Activity}

1,1-Diphenyl-2-picrylhydrazyl (DPPH) is a stable free radical. DPPH gained its stability as free radical molecules due to the delocalization of odd electron throughout the molecules. This more steadied DPPH produce 
intense violet colour in ethanol solution. The antioxidant present in the extracts reacts with DPPH free radical solution and converts them into reduced form either by donating hydrogen atom or transferring electron followed by proton. This oxidation reaction is accompanied with loss of violet colour which can be measured quantitatively at $517 \mathrm{~nm}$ [13]. The AgNPs exhibited a significant dose dependent inhibition of DPPH activity as compared to Hydrophila auriculata leaf extract. The potential of Lascorbic acid to scavenge DPPH radical is directly proportional to the concentrations. AgNPs has potential antioxidant activity than Hydrophila auriculata extract and near to standard (Fig. 1). Similar results was also observed in Soumya Menon [14] studies.

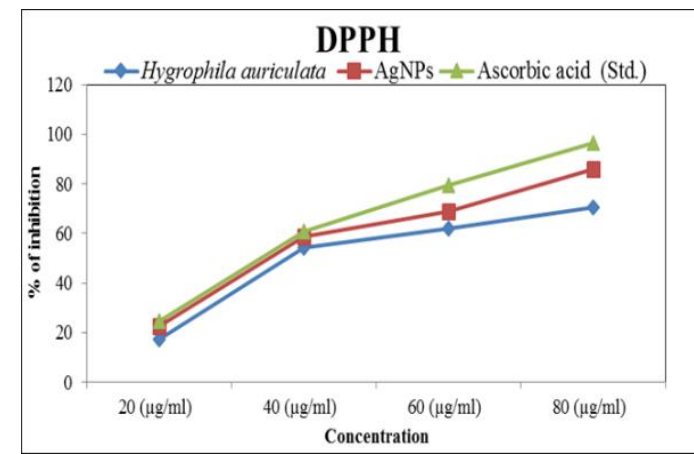

Fig. 1 DPPH radical scavenging activity of Hygrophila auriculata leaves extract and AgNPs at different concentrations

\subsection{Total Antioxidant Activity}

Total antioxidant capacity of AgNPs and Hydrophila auriculata leaf extract are expressed as the number of equivalents of ascorbic acid. The phospho molybdenum technique was constructed on the reduction of Mo (VI) to Mo (V) by the antioxidant compound and the formation of a green phosphate Mo (V) complex with a maximum absorption at $695 \mathrm{~nm}$. The assay is successfully used to quantify vitamin $\mathrm{E}$ and as it is being simple and independent of other antioxidant measurements commonly employed, it was decided to extend its application to plant extract [9]. Moreover, it is a quantitative one, since the antioxidant activity is expressed as the number of equivalents of ascorbic acid. The total antioxidant activity of Hydrophila auriculata leaf extract, AgNPs and ascorbic acid was dose dependent manner. The AgNPs exhibited a significant dose dependent inhibition of DPPH activity. AgNPs has potential antioxidant activity than Hydrophila auriculata extract and near to standard (Fig. 2).

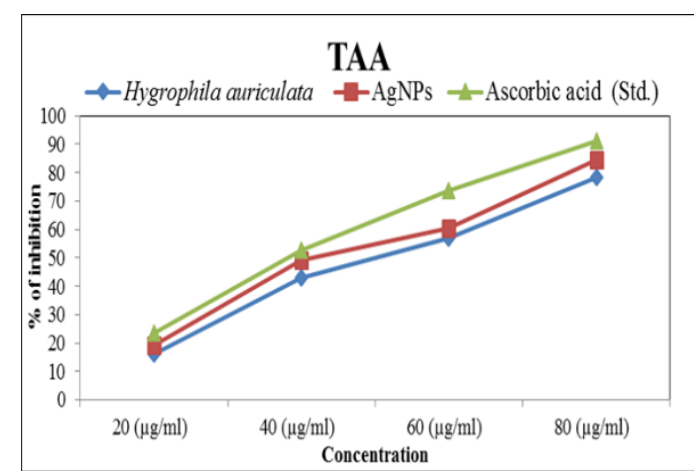

Fig. 2 Total antioxidant activity of Hygrophila auriculata leaves extract and AgNPs at different concentrations

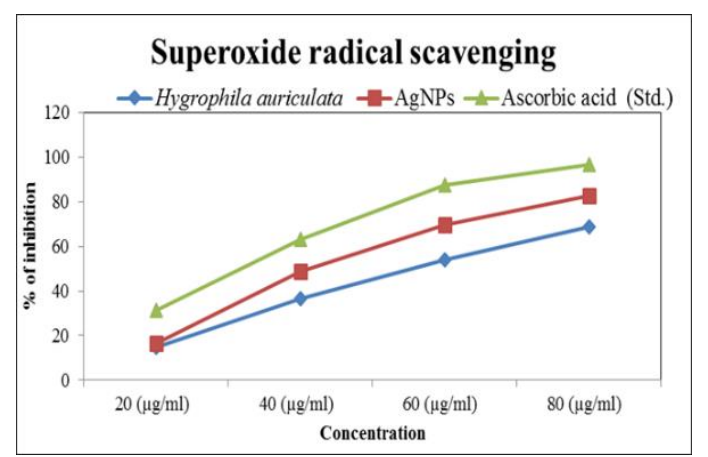

Fig. 3 Superoxide scavenging activity of Hygrophila auriculata leaves extract and AgNPs at different concentrations

\subsection{Superoxide Scavenging Activity}

Superoxide is biologically important since it can decompose to form stronger oxidative species such as singlet oxygen and hydroxyl radicals, is very harmful to the cellular components in a biological system [15]. The superoxide scavenging activity of Hydrophila auriculata leaf extract, AgNPs and ascorbic acid was increased markedly with the increase of concentrations. AgNPs has potential superoxide anion scavenging activity than Hydrophila auriculata extract and near to standard (Fig. 3).

\subsection{Ferrous Ion Chelating Activity}

The metal chelating assay involves color reduction which in turn determines their chelating ability of synthesized nanoparticles for ferrous ions. The formation of the ferrozine $-\mathrm{Fe}^{2+}$ complex is interrupted in the presence of Hydrophila auriculata leaves extract, AgNPs and ascorbic acid was increased markedly with the increase of concentrations. Thus the decrease in the absorbance at $562 \mathrm{~nm}$ indicated high levels of iron binding potential and antioxidant activity of the nanoparticles. AgNPs has potential ferrous ion chelating activity than Hydrophila auriculata extract and was near to standard (Fig. 4).

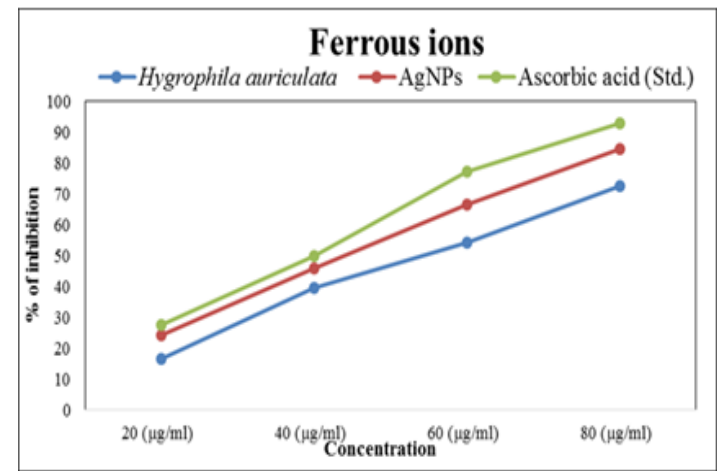

Fig. 4 Ferrous ion chelating activity of Hygrophila auriculata leaves extract and AgNPs at different concentrations

\subsection{Reducing Power Activity}

The reductive effect of Hydrophila auriculata leaves extract, AgNPs and ascorbic acid increased with increasing dosage (Fig. 5). All the doses showed significant activities near to the control exhibited greater reducing power, indicating that Hydrophila auriculata consist of hydrophilic polyphenolic compounds that cause the greater reducing power. Since the reducing power activity of the compounds could serve as a significant indicator of the antioxidant potential, we assessed this property by measuring the ability of the extract to transform $\mathrm{Fe}^{3+}$ to $\mathrm{Fe}^{2+}$ and to donate an electron. The ability of the extracts to reduce $\mathrm{Fe}^{3+}$ could be attributed either to the reducing agents such as number of phenolic groups or position of the hydroxyl molecule on these groups.

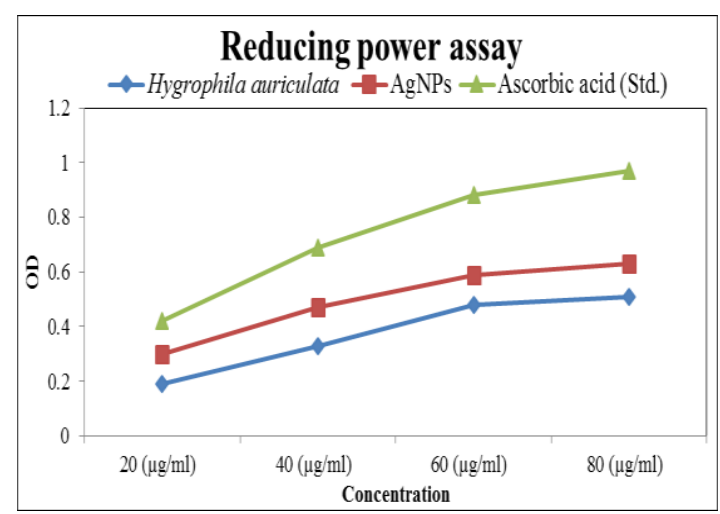

Fig. 5 Reducing power activity of Hygrophila auriculata leaves extract and AgNPs at different concentrations

Antioxidant activity increased proportionally to the polyphenol content. The phenols contain hydroxyls that are responsible for the radical scavenging effects mainly due to the redox properties [16]. Present results are in agreement with [17] studies who reported that Antioxidant, cytotoxic and antimicrobial activities of green synthesized silver nanoparticles from crude extract of Bergenia ciliate. 


\section{Conclusion}

Present study concluded that the greatest in vitro antioxidant activity of silver nanoparticles was observed as compared with Hydrophila auriculata leaf extract.

\section{References}

[1] A.V. Badarinath, K.M. Rao, C.M.S. Chetty, V. Ramkanth, T.V.S. Rajan, K. Gnanaprakash, A review on in-vitro antioxidant methods: comparisons, correlations and considerations Int. J. Pharm. Tech. Res. 2(2) (2010) 12761285.

[2] S. Velavan, Free radicals in health and diseases - A mini review, Pharmacol. Newslett. 1 (2011) 1062-1077.

[3] M.A. Smith, C.A. Rottkamp, A. Nunomura, A.K. Raina, G. Perry, Oxidative stress in Alzheimer's disease, Biochim. Biophys. Acta. 1502 (2000) 139-144.

[4] O.E. Blokhina, Virolainen, K.V. Fagerstedt, Antioxidant, oxidative damage and oxygen deprivation stress: A review, Ann. Bot. 91 (2003) 179-194.

[5] M.D. Nur Alam, M.D. Nusrat Jahan Bristi, Rafiquzzaman, Review on in vivo and in vitro methods evaluation of antioxidant activity, Saudi Pharmaceut. Jour. 21 (2013) 143-152.

[6] R. Arunachalama, S. Dhanasingha, B. Kalimuthua, M. Uthirappana, Chellan Rosea, A.B. Mandal, Phytosynthesis of silver nanoparticles using Coccinia grandis leaf extract and its application in the photocatalytic degradation, Colloid. Surf. B: Biointerf. 94 (2012) 226-230.

[7] K. Shimada, K. Fujikawa, K. Yahara, T. Nakamura, Antioxidative properties of xanthum on the autoxidation of soybean oil in cyclodextrin emulsion, Jour. Agri. Agri. Food Chem. 40 (1992) 945-948.

[8] F. Liu, C.V.E. Ooi, S.T. Chang, Free radical scavenging activity of mushroom polysaccharide extracts, Life Sci. 60 (1997) 763-771.
[9] P. Prieto, M. Pineda, M. Aguilar, Spectrophotometric quantitation of antioxidant capacity through the formation of a phosphor molybdenum complex Specic application to the determination of vitamin E, Anal. Biochem. 269 (1999) 337 341.

[10] T.C.P. Dinis, V.M.C. Madeira, L.M. Almeidam, Action of phenolic derivates (acetoaminophen, salycilate, and 5-aminosalycilate) as inhibitors of membrane lipid peroxidation and peroxyl radicals scavengers, Arch. Biochem. Biophys. 315 (1994) 161-169.

[11] M. Oyaizu, Studies on products of browning reactions: antioxidant activities of products of browning reaction prepared from glucose amine, Jap. Jour. Nutri. 44 (1986) 307-315.

[12] M. Ravishankar, V. Christibai Juliet Ester, Green synthesis and evaluation of antimicrobial activity of silver nanoparticles from Hygrophila auriculata leaf extract, J. Nanosci. Tech. 4(3) (2018) 380-382.

[13] A.M. Nuutila, R.P. Pimia, M. Aarni, K.M.O. Caldenty, Comparison of antioxidant activities of onion and garlic extracts by inhibition of lipid peroxidation and radical scavenging activity, Food Chem. 81 (2003) 485-493.

[14] Soumya Menon, S. Happy Agarwal, S. Rajesh Kumar, Venkat Kumar, Green synthesis of silver nanoparticles using medicinal plant Acalypha indica lea extracts and its application as an antioxidant and antimicrobial agent against foodborne pathogens, Int. Jour. Appl. Pharm. 7 (2017) 5-8.

[15] M. Korycka-Dahl, M. Richardson, Photogeneration of superoxide anion in serum of bovine milk and in model systems containing riboflavin and aminoacids, Jour. Dairy Sci. 61 (1978) 400-407.

[16] A.A. Adedapo, F.O. Jimoh, S. Koduru, A.J. Afolayan, P.J. Masika, Antibacterial and antioxidant properties of the methanol extracts of the leaves and stems of Calpurnia aurea, BMC Comp. Altern. Med. 8 (2008) 53-61.

[17] Abdul Phull, Abbas, Qamar Ali, Attarad Raza, Hussain kim, et al., Antioxidant cytotoxic and antimicrobial activities of green synthesized silver nanoparticles from crude extract of Bergenia ciliata, Future Jour. Pharm. Sci. 2 (2016) 42-48. 